\title{
BEHAVIOUR-BASED ASSESSMENTS IN THE SPECIAL FORCES ENVIRONMENT: A PROCEDURAL REVIEW
}

\author{
Stephanie van Wyk and Renier du Toit \\ Military Psychological Institute
}

\begin{abstract}
The South African Special Forces is a grouping of highly trained, motivated and dedicated soldiers who execute specialised tasks that ordinary infantry soldiers are not trained or required to conduct. The milieu in which Special Forces operators function is notoriously challenging as these forces could deploy for a few days or several months or longer in any type of environment. It is therefore essential that the correct candidates be selected to function in these environments. The aim of the officer's potential assessment (OPA) is thus to select candidates with the physical, cognitive, emotional and psychological fitness to be trained as South African Special Forces operators and officers. The study on which this article is based, explored the development of the behavioural assessments during the South African Special Forces officers' selection process as a method and model for the review and design of assessment centres from a holistic, detailed perspective.
\end{abstract}

Keywords: Behavioural observation, Special Forces, assessment centres, rating scales, officers

\section{Introduction}

The South African Military Health Service (SAMHS) forms a key element in the support of the South African National Defence Force's operational readiness by sustaining the physical, mental and social well-being of a fighting force. ${ }^{1}$ Military psychologists are employed by SAMHS to provide various services within unit lines as well as during operational deployments. Psychologists functioning within the specialist selection environment bear the responsibility of selecting Special Forces officers to execute highly specialised tasks, which ordinary infantry soldiers are not trained or required to conduct. ${ }^{2}$ In selecting the potential officer candidates, job-related predictors and criterion constructs are assessed by means of an assessment centre approach to determine whether the potential candidates demonstrate the necessary cognitive and personal qualities to function successfully in the strenuous Special Forces environment. 


\section{Theoretical background}

Modern labour legislation expects the 'reasonable employer' to assess prospective workers by using assessments, which focus on the inherent requirements of the job. ${ }^{3}$ Assessment centres are ideally suited to address this expectation as they are tailored to the requirements of the organisation to select candidates for a specific role or function. ${ }^{4}$ In addition, this method employs multiple assessment techniques and multiple assessors to measure job-specific behaviours and skills as well as personality and attitudinal dimensions. ${ }^{5}$

Considering labour legislation requirements as well as the design of assessment centres, it is imperative to look firstly at the attributes of the job before one considers the screening of candidates. ${ }^{6}$ The first step in developing an assessment centre is therefore a job analysis and competency modelling process. ${ }^{7}$ During this process, the analysis focuses on the job situation, tasks and contextual factors as well as identifying the behaviours, skills and attributes, which adequately differentiate between effective and less effective performance in the job. ${ }^{8}$ Once the information has been analysed, the critical job competencies are formulated and selected. During this process, it is essential to ensure that the formulated competencies are clearly defined and expressed in terms of behaviour that can be observed on the job. ${ }^{9}$

The next step in the process is to select and develop assessment techniques to elicit a variety of behaviours and other information relevant to the selected competencies. ${ }^{10}$ These assessment techniques require participants to respond behaviourally to situational stimuli and can be administered in a variety of formats, such as paper, video, audio, computers, face-to-face encounters, telephonic conversations or via the internet. Examples of such behavioural simulation exercises include in-basket exercises, group exercises, case studies, role-play exercises, presentations and factfinding exercises. ${ }^{11}$

Best practice guidelines regarding assessment centres also stipulate that assessment centres must contain multiple assessments to provide various opportunities for participants to display job-related behaviour in terms of the selected competencies. ${ }^{12}$ The identified competencies are then mapped according to these various assessment techniques to be administered during the assessment centre process. This is known as the "assessment matrix", which provides an overview of the competencies to be assessed in relation to the chosen assessment techniques. ${ }^{13}$

During the assessment process, the candidate's behaviour is observed, noted and recorded by listing examples of the observed behaviour for each candidate. ${ }^{14}$ The observed behaviour is then classified into meaningful categories, such as dimensions, competencies, skills and abilities and knowledge in order to be evaluated. ${ }^{15}$ Structured rating forms, specifically designed for the behavioural simulation exercise, facilitate this process by providing a list of behavioural indicators related to each of the selected competencies measured. ${ }^{16}$ 
The structured rating forms serve to guide the assessor in classifying the observed behaviour under the relevant competencies to be rated. ${ }^{17}$ These rating instruments may be expressed Likert-type scales, such as traits scales and behavioural observation scales (BOS) or behaviour-anchored rating scales (BARS) or behaviour expectation scales (BES). ${ }^{18}$

Trait scales are generally presented in a Likert-type format and consist of personality traits, such as commitment, initiative or loyalty. The observer evaluates the candidate on each trait, e.g. $5=$ above average, $3=$ average, and $1=$ below average performance. ${ }^{19}$ Research, however, postulates that BOS and BARS or BES are preferred over trait scales as the former scales address work-related, verifiable behaviours, which are perceived to be more objective and fair than trait scales. Behaviour-based scales have also been found to result in better-quality performance feedback. $^{20}$

BOS are Likert-type scales based on specific behaviours identified during a critical incident job analysis. ${ }^{21}$ Each interval is represented by a label definition and an adjective. The observer focuses on the frequency of the observed behaviour, which can be totalled to produce an overall score. ${ }^{22}$ It is important to note that these instruments need to be able to discriminate between nearly similar levels of behaviour. ${ }^{23}$ However, a 3-point or a 5-point scale tends to cluster the majority of the population at the centre of the scale. ${ }^{24}$ Sawardekar cautions that this destroys the purpose of the rating, i.e. to distinguish between the various candidates. ${ }^{25}$

BARS or BES aims to capture multidimensional and behaviour-specific aspects of performance. ${ }^{26}$ BARS was originally thought of as BES; however, Bolt states that BES differs from BARS as BES describes behaviour expectations rather than neutral behaviours as with BARS. ${ }^{27}$ Nevertheless, both scales use a critical incident technique to identify specific examples of effective and ineffective work performance behaviours. ${ }^{28}$ These behaviours are identified by appropriate subject matter experts or job incumbents and are formulated in their own terminology. ${ }^{29}$ The 'anchors' reflect behaviours expected of the candidate during observations relating to outstanding, average and unacceptable behaviour. ${ }^{30}$ This ensures that the assessors are familiar with the behaviours associated with each rating scale anchor, which therefore eliminates much of the ambiguity found in rating scales based on key traits. ${ }^{31}$ Another advantage of BARS is that it shows less leniency error and less halo effect than Likert-type scales. ${ }^{32}$ The involvement of assessors in the development process is viewed as an added bonus as the assessors are likely to feel that they have some personal investment in the scales. ${ }^{33}$ Even assessors who did not participate in the scale development may view the scales favourably because of their reliance on colleagues' feedback. ${ }^{34}$ However, one of the main criticisms of BARS is that the middle score band is not detailed enough as good and poor performance behaviours are more easily described than average behaviours. ${ }^{35}$ 
When deciding on the scale, the following criteria apply:

- the rating scale must be easy to use during behaviour evaluation;

- it must be comprehensible to the observers, participants and any other feedback recipient; and

- it must facilitate validation studies. ${ }^{36}$

Assessor training can be considered another critical element to the success of an assessment centre. Assessors are trained in a group, and their assessments are standardised to have a single frame of reference, which maximises inter-rater reliability. ${ }^{37}$ There are two forms of assessor training, namely behavioural training and frame-of-reference training. ${ }^{38}$

Behavioural training focuses on what constitutes behaviour. The assessors must be able to distinguish clearly between behaviour and someone's interpretation of behaviour. They need to be sensitised not to use generalised statements or interpret behaviour or try to describe the candidate's underlying personality. ${ }^{39}$ As such, the observers are familiarised with the assessment centre process, i.e. the need to observe, record, classify and evaluate the behaviour of participants who complete a variety of behavioural simulation exercises. This technique is referred to as ORCE, and allows assessors to evaluate the observed behaviour accurately and reliably. ${ }^{40}$

The assessors furthermore need to understand the behaviours associated with the competencies in order to transfer these behavioural examples to the rating sheets. ${ }^{41}$ Training in this regard is known as frame-of-reference training. In this form of training, guidance is provided on ratings and calibrating scores in accordance with specific behavioural indicators linked to the selected competencies. ${ }^{42}$ According to Jackson, Atkins, Fletcher and Stillman, this allows for standard setting and improved assessments. ${ }^{43}$ Schlebush and Roodt state that the outcomes of the observer training are therefore focused on enabling observers to: ${ }^{44}$

- classify behaviour objectively during interactive and paper-based simulations, according to the competencies being evaluated;

- evaluate classified behaviour fairly according to norms;

- report the evaluated behaviour effectively;

- observe behaviour during interactive simulations correctly; and

- note behaviour accurately during interactive simulation.

During the assessment centre, multiple assessors rate each participant's performance across the various behavioural simulation exercises independently against the selected competencies. ${ }^{45}$ To improve objectivity, the assessor should not observe a person whom he or she knows. ${ }^{46}$ In addition, each assessor should observe each participant in at least one behavioural simulation exercise. ${ }^{47}$

The cognitive demands placed on the assessor should also be considered as this could affect the effectiveness of the assessment. These demands are typically 
associated with the assessor-participant ratio as well as the number of competencies to be assessed. ${ }^{48}$ Although there is no consensus in the literature regarding the specific number of competencies to be measured, as a guideline, it is recommended that between four and six competencies be measured for each behavioural simulation exercise. ${ }^{49}$ Literature postulates that lowering the assessor-participant ratio as well as minimising the number of dimensions to be assessed, could lower the cognitive demands placed on the assessor. ${ }^{50}$

Each exercise typically measures three to six dimensions although the assessment centre as a whole may consider more dimensions. ${ }^{51}$ On completion of the exercise and evaluations, the assessment centre scores are determined by combining the data for each candidate by means of either consensus meeting between assessors or statistical integration. ${ }^{52}$

Standardisation is particularly important for assessment centres used for selection purposes. ${ }^{53}$ The procedures for assessment centre administration must be controlled to ensure that all participants have the same opportunity to demonstrate behaviour related to the designated competencies. ${ }^{54}$ This relates to the instructions for behaviour simulation exercises, time limits, exercise materials, conditions (e.g. facilities used), role-player behaviour, number of participants in group exercises, questions asked by assessors during presentations, the sequence of exercise administration, and the scoring procedures. ${ }^{55}$

\section{Behaviour-based assessments in the Special Forces environment}

Within the military context, assessment centres are utilised in various environments to select suitable candidates for specific roles and/or functions. The SANDF Special Forces is one force element that actively employs assessment centres for the selection of candidates. The term 'special operations forces' usually refers to small, carefully selected military, paramilitary and civilian units manned by personnel with unique and unusual skills. They are well trained for specific rather than general purposes, and undertake unusual tasks that ordinary units might accomplish only with far greater difficulty and far less effectiveness. ${ }^{56}$

The primary mission of the Special Forces operator is to execute tasks as a member of an elite team, deep inside enemy territory. These members are required to implement unconventional operations by air, land or sea during war or peacetime. Duties include:

- advanced reconnaissance operations and intelligence information gathering;

- conducting raids and invasions into enemy territory;

- laying and detonating explosives for demolition targets;

- locating, identifying, defusing and disposing of ordnance; and

- operating and maintaining sophisticated communications equipment.

These members therefore often have specialised training in swimming, diving, parachuting, survival, emergency medicine and foreign languages. ${ }^{57}$ 
In addition to the abovementioned requirements, members identified to become officers in the Special Forces environment are faced with greater leadership responsibilities than non-commissioned officers. Within their role as officers, these members must be able to liaise, design, coordinate and command the military use of Special Forces personnel and capabilities during Special Forces operations. ${ }^{58}$

Due to the stringent selection that these members must undergo to become Special Forces operators, very few officers attend the selection process and qualify as Special Forces operators. As a result, Special Forces is often required to select and develop non-commissioned officers (NCOs) to become officers. Consequently, the Special Forces selection process is structured in such a manner that members can be selected as Special Forces operators with an additional selection phase to identify potential officers from the pool of candidate operators. To address this requirement, the Special Forces School conducts an officer's potential assessment (OPA), in the form of an assessment centre, three weeks before the Special Forces selection. ${ }^{59}$

During the OPA, observations of each candidate takes place over a period of one week in order to observe all phases of a typical Special Forces deployment. The OPA process allows for two selection boards. All members have the opportunity to prove their competence during the first two days of the selection process. The initial selection board serves to identify members who do not meet the selection criteria. Members who are not successful during this phase, are returned to their home units. ${ }^{60}$

The final two days of the selection process entails extensive assessment of the candidates with specific focus on their ability to function within operational environments. The same process is followed as with the initial selection board. Successful candidates during this phase will continue to the Special Forces selection process, and after completing this selection, will be accepted to complete the Special Forces basic training cycle. ${ }^{61}$ This process is illustrated in Figure 1:

Figure 1.Special Forces officer assessment process. ${ }^{62}$

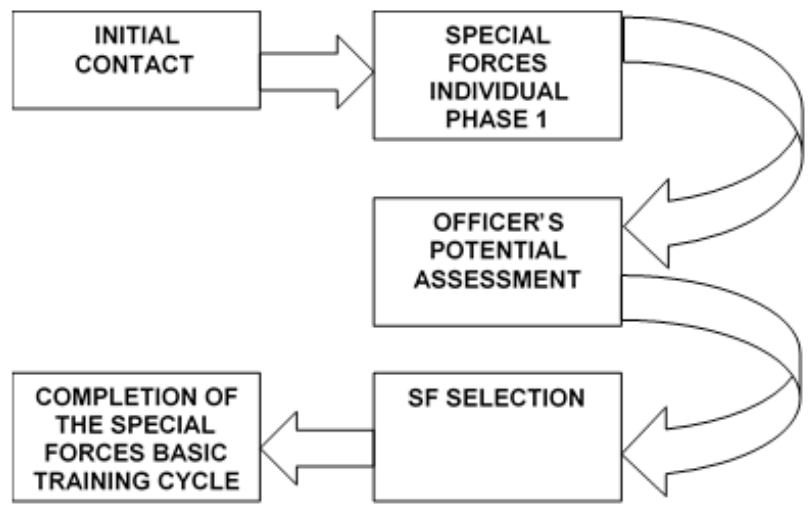


The OPA assessment process provides the opportunity to assess each candidate within a changing environment in a series of specifically tailored job-related assessment activities focused on the Special Forces deployment preparation and planning process. ${ }^{63}$ These activities include:

- A simulated job interview, which allows the audience to get to know the candidates in terms of their civilian and military background.

- Simulation exercises with troops, focusing on outdoor activities that are practical by nature, and which challenge candidates to conduct problemsolving activities in order to complete a scenario successfully by overcoming physical obstacles based on teamwork. All candidates are required to complete three of these behavioural exercises as it provides an opportunity to assess the candidate practically during problem-solving and leadership processes.

- Tactical exercises without troops (TEWT) are simulation exercises based upon a scenario similar to the type of operations that are conducted by Special Forces. Each officer candidate is provided with all the relevant maps and information to assess the situation correctly and to decide upon a course of action. All candidates are required to complete two of these exercises prior to the first selection board. The successful candidates will then proceed to complete two additional TEWT exercises and to develop one into an operational orders presentation.

- During the operational orders presentation, the candidate is required to provide verbal orders based on the candidate's appreciation and problem solving during the TEWT exercise.

- A case study is used to assess the candidate's ability to analyse problems or past operations, and to comment on the material according to a questionnaire. The case study is in the form of a video, which needs to be analysed.

- Background activities are included in the selection process to simulate the mentally and physically taxing environment of the Special Forces. These activities include two comprehension tests and four essays. The activities are scheduled in between the simulation exercises to induce mental fatigue. Physical training (PT), such as physical fitness tests and route marches, adds to the already demanding schedule to induce further physical fatigue.

The OPA selection is completed in front of an audience, which consists of multiple observers. The assessors can be divided on two grounds: firstly their rank structures and secondly their specialisation fields. This division informs the assessors regarding their role in the assessment process, as well as their main areas of focus during the assessment. 
All assessors, regardless of their rank or specialisation fields, are required to attend behavioural training as well as frame-of-reference training to ensure that all assessors understand both the behavioural and procedural requirements of the assessment centre. The assessors all complete the same rating sheet with a slight difference between the two groupings in terms of the weights allocated to their ratings.

Considering the best practices as identified in literature, the focus of the OPA redesign was to scrutinise the current selection process in order to streamline the assessment process, reduce rater cognitive overload as well as to clarify and operationalise competencies with practically observable, work-specific behaviours. In addition to the selection, the measure should also be able to identify the candidate's developmental areas.

\section{Aim}

The purpose of this article is to describe the procedural review of the OPA for the Special Forces selection process as a method and model for the review and design of assessment centres from a holistic, detailed perspective.

\section{Methodology}

A four-stage model was utilised to analyse, design, implement and evaluate the OPA. The review process entailed a needs analysis, competency redesign, as well as the development of new instruments, which were aligned with the guiding policies. The redesigned assessment centre was implemented and evaluated on three occasions to ensure client satisfaction. During this process, a panel from the Special Forces School as well as research and industrial psychologists scrutinised the selection and assessment process as well as the instruments being utilised. This contributed to the development of enhanced assessment instruments and ensuring the alignment of these instruments with updated profiles, updated exercises as well as with the policies and guidelines of the Special Forces school. The process followed during the redesign was based on the four-stage model illustrated below:

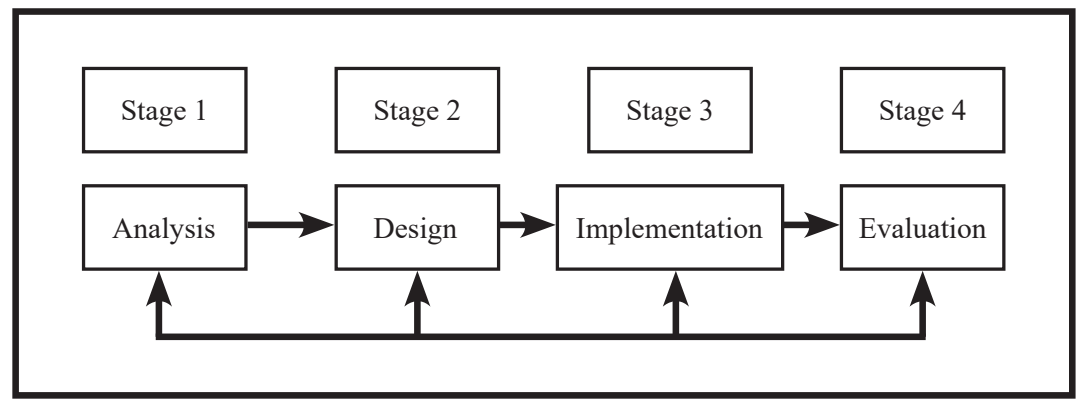

Figure 2. The basic design model. ${ }^{64}$ 
Stage 1: Analysis - the analysis stage focused on the Special Forces officer's profile as well as the organisational context to determine the specific needs and objectives for the redesign of the assessment centre.

Stage 2: Design - during the design stage, the competencies, assessment process as well as instruments were formulated and redesigned based on the objectives identified during the analysis stage. These measures were further aligned with the guiding policies.

Stage 3: Implementation - the assessment centre was implemented in its entirety, allowing the design team to observe the process as a whole in order to determine whether there were any process and/or procedural glitches. The OPA design cycle was implemented on three occasions during a 20 -month period, which provided valuable feedback to consider and integrate, thereby ensuring acceptance and client satisfaction.

Stage 4: Evaluation - the OPA process and instruments were evaluated after each implementation to determine whether the assessment centre succeeded in achieving the assessment objectives. Each evaluation served as an indication for further actions to be taken.

\section{Findings}

Stage 1: Analysis - the analysis showed that the existing job profile and assessment exercises were sufficient for the identification of competent candidates. However, various challenges were highlighted with regard to the assessment process and rating instruments, namely:

- Policy and guidelines - the OPA process was found to adhere to the policy requirements. The job profile was also found to be accurate and valid.

- Competency alignment - the results showed that the assessment centre measured all the competencies identified for the Special Forces officer's profile during all the exercises. This resulted in a lack of focus with regard to the competencies to be measured. It furthermore affected the assessors who reported a sense of overload as each competency needed to be assessed with each exercise in this format.

- Assessor training - during the analysis, it was reported that the assessor training was not viewed with the necessary seriousness as the assessors were merely 'going through the motions'.

- Rating sheets - a generic rating sheet was utilised to measure all the identified competencies during all the exercises. This approach was cumbersome, as some of the exercises did not elicit the behaviour identified in the rating sheet sufficiently. The large volume of information contained in the rating sheet combined with the number of candidates to be assessed further increased the 
burden placed on the assessors. In addition, some assessors relied heavily on the competency elements stipulated in the definition on the rating sheet to allocate marks. This was problematic, as assessors relying on this method did not consider whether the behaviours were presented consistently nor did they consider the quality of such behaviour.

- Rating scale - the competencies were assessed by means of a 5-point Likerttype scale, which measured behaviour in terms of:

- behaviour between 0 and 1 = unsuitable;

- behaviour between 2 and 4 = potential/decision; and

- behaviour between 4 and 5 = suitable.

From the results, it was evident that the abovementioned options complicated the decision-making process, especially in determining where on the scale the candidate's behaviour should be rated. Furthermore, vague descriptions such as 'potential/decision' contributed to the ambiguity of the scale. Finally, the generic rating sheet with the underlying 5-point Likert-type scale made the clear identification of specifically delineated developmental areas difficult. This predominantly stemmed from the phenomenon of central tendency, which was found with the ratings from the assessors. This was further exacerbated by the fact that the calculation of a final score for each candidate based on a combination of scores from the various assessors also led to the phenomenon of central tendency.

Based on this analysis, the main objectives identified to be addressed during the design phase included:

- developing a competency matrix to ensure that the competencies identified are individually measured on a minimum of three occasions by means of exercises that elicit the required behaviours;

- reviewing the assessment exercises to ensure that the expected behaviour is elicited, and redesigning the exercises if required;

- developing exercise-specific rating sheets;

- focusing on effective and ineffective behaviours to identify suitable candidates as well as possible areas for development; and

- providing an assessment guide as well as an updated policy document with regard to the preparation, management and execution of future assessments for standardisation purposes.

Stage 2: Design - the design phase focused on addressing the objectives identified during the analysis phase. The following matters were addressed during the design phase: 
- Policy and guidelines - the existing policies were redesigned to include new assessment requirements. The document was formulated to stipulate clearly requirements for the preparation, management, execution, roles and responsibilities for implementing the assessment centre. This was done to ensure that the OPA would be implemented consistently according to set standards.

- Assessment process - with regard to the assessment process, a detailed policy document was updated with regard to the implementation requirements for a standardised implementation of the OPA assessment process.

- Competency alignment - a review of the job profile and a competency modelling process were utilised to identify relevant behaviours, skills and attributes to be measured on various occasions during the assessment centre process. Twelve competencies were identified to be measured during the assessment centre, and were aligned with the exercises. This competency matrix focused on moving away from the generic rating sheet utilised previously. The redesign required a total of five exercises to be completed before each selection board. These exercises included the timefiller exercises, which were previously not assessed. This contributed to a focused approach, limiting the number of competencies to be assessed per exercise and thereby reducing the cognitive demands placed on the assessors. The design nevertheless ensured that each candidate would be afforded a minimum of three opportunities to present behaviour related to the competency measured before a final ruling can be made with regard to the candidate's competence.

- Assessment exercises - activities previously viewed as time-fillers to induce mental and physical fatigue were not included in the overall assessment of the candidate's performance. During the design phase, it was decided to include these exercises to obtain more qualitative inputs regarding the candidates' performance from natural observation, e.g. the candidates have to complete these exercises in their own time whilst being overloaded with simulations and physical training. Aspects such as the candidates' work ethos, motivation and conduct can be observed during these exercises without the candidates' awareness. The existing simulation exercises were found to be sufficient to elicit the behavioural requirements identified during the competency modelling process. The alignment of the competencies to the relevant rating sheets as well as with the correct exercise to elicit the behavioural requirements was the main focus of this phase of the redesign process.

- Assessors and assessor training - during the design phase, the assessors were involved in the competency as well as rating sheet designs. This allowed a greater understanding with regard to the assessment centre approach followed and resulted in the assessors feeling vested in the process. Being 
involved also led to a stronger focus and emphasis with regard to the assessor training, which was previously not viewed with the necessary seriousness. To ensure that all assessors are proficient in utilising these instruments, the policy document was updated to include OPA-specific behaviour observation training as a prerequisite for assessors. The behaviour observation training was also redesigned to include behavioural training and frame-of-reference training to focus on the updated competencies, exercises, rating sheets as well as observational requirements.

- Rating sheets and scales - based on the competency matrix, exercisespecific rating sheets were designed and developed utilising a combination of BES and BARS methodology. During this process, the Special Forces panel determined effective and ineffective behaviours to be measured for each competency. Twelve behaviours epitomising performance on various competencies were structured in such a manner that the assessors could indicate whether the behaviours were observed or not. The redesign of the rating sheet centred on providing an instrument that is user-friendly whilst measuring the required behaviour.

- The development of new rating sheets focused on the primary concerns with regard to the rating sheet identified during the analysis phase. The redesign thus focused on the inability of the instrument in identifying specific developmental areas as well as the phenomenon of central tendency stemming from the use of the instrument.

- In order to facilitate the elicitation of clear developmental areas, the 5-point Likert-type scale was removed and an alternative scoring system adopted. For the alternative scoring system, items on each competency were structured to reflect both effective (positive) and ineffective (negative) behaviours. These items were designed based on the effective and ineffective behaviours determined by the Special Forces panel. Each competency on the rating sheet was then formulated to contain an equal number of effective and ineffective behaviours with assessors merely being required to tick each of the behaviours once they had been observed.

- With this system, each candidate is allocated a score for effective and ineffective behaviour for each competency assessed. Once the effective and ineffective scores for the candidate on each competency have been determined, they are compared utilising a 1:2 ratio and converted to a 4-point scale as follows:

- $\quad 4$ = mostly effective behaviour with little ineffective behaviour with a ratio $>2$;

- $\quad 3=$ more effective than ineffective behaviour with a ratio of $<2$;

- $\quad 2=$ more ineffective than effective behaviour with a ratio $<2$; and

- $\quad 1=$ mostly ineffective behaviour with little effective behaviour with a ratio $>2$. 
- The new rating sheet and underlying scoring system firstly served to eliminate the ambiguity experienced with regard to the rating of candidates on the 1-5 Likert-type scale and the difficulty associated with deciding where on the scale to rate a candidate's behaviour. Furthermore, the vagueness of the previous descriptions was also eliminated. Finally, the introduction of a 4-point scale based on the ratio of effective versus ineffective behaviours, served to eliminate the phenomenon of central tendency that was experienced with the previous 5-point Likert-type scale and allowed for the clear identification of specific developmental areas for each candidate based on the competencies assessed.

- Data integration - specific focus was placed on the data integration as the design allowed for both statistical integration as well as a round-table discussion to be implemented. This provides an overall rating as well as clarity with regard to the candidate's performance per competency. This integration furthermore allows the determination of the candidate's overall performance as measured against the profile. This contributed to identifying effective and ineffective behaviours as well as the formulation of a developmental plan if so required.

Stage 3: Implementation - the updated OPA was conducted in its entirety, allowing the designers to observe the programme as a whole. This allowed both the design team as well as the client to determine whether the updated process, competency modelling as well as rating sheets met the expected outcomes. This process was implemented on three occasions over a 20 -month period. Feedback was obtained after each implementation and additional corrective actions were taken.

Stage 4: Evaluation - after the initial implementation, feedback was obtained from the client. This showed that the process as well as the redesigned rating sheets was working well. However, the formulation and terminology used for behavioural descriptors required further clarification as the client expressed a need to incorporate the exact meaning of descriptors in their own terminology. Upon the feedback, required changes were made during a cooperative work session to formulate the behavioural descriptors from the client's perspective. This was implemented during a second phase. Again, feedback was provided and it appeared that the measure was well received by the client and functioning according to expectation. A third implementation was then utilised to confirm that the measure meets all requirements and provides a fair and accurate measurement of the candidates' performance.

\section{Discussion}

From the review process followed, it was clear that the systematic holistic, fourstage model that was utilised was effective in identifying the caveats within the selection process and allowed for the identification, analysis, intervention and evaluation of 
elements to enhance the selection process ranging from the organisational level to the practical level.

In conjunction with the utility of the model in identifying and addressing concerns on various levels systematically, the procedure encapsulated within the model required close interaction and cooperation with the client, Special Forces, as subject matter experts throughout in terms of the guiding policies, exercises, competencies and accompanying critical work-related behaviours as stipulated in the job profile. This close interaction at every stage of the process culminated in an informed, complete and well-rounded perspective at every step of the process as it allowed for the integration of operational expertise of the client with psychological expertise in terms of selection. The involvement of the client and assessors at every step of the process served to generate significant acceptance from the client regarding the final product and the implementation and use of the redesigned OPA process and instruments. This acceptance ultimately translated into greater trust and personal investment of the client in the OPA process as a whole as well as greater understanding of the psychological procedures, assessment and principles of the assessment centre approach.

On a practical level, the assessment centre approach utilised during the OPA, moved from a traditional dimension-based assessment centre to a task- or role-based assessment centre. This was achieved by relying on Special Forces assessors to identify critical work-related behaviours for the various competencies as stipulated in the job profile.

The major advantage of such measures is that the assessor has to make fewer inferences about the candidate. The assessor is cast more in the role of observer and less in the role of judge. This approach also reduces subjective ratings as the observer is forced to make a thorough evaluation of a candidate rather than emphasising only those points that he or she can recall.

Based on the data supplied by the Special Forces assessors, the assessment process also reduced the number of competencies assessed during each exercise, thereby minimising the cognitive demands placed on the assessors.

Involving the assessors during the redesign process contributed to the understanding of and commitment to the use of the rating instruments. Complaints regarding the understanding and appropriateness of items were minimised. According to literature, ease of use also increases the chances of the documentation being completed comprehensively. ${ }^{65}$ Correct and comprehensive use of the simulation documents furthermore contribute to the overall reliability of the simulation results. ${ }^{66}$

The sense of personal investment in the design of the rating instrument as well as assessment centre process furthermore resulted in a favourable approach from the assessors - not only to the selection but towards assessor training and candidate development as well. 
One of the major advantages of the new approach centres on the developmental focus that underlies the assessment. The behavioural anchors and identification of ineffective behaviours can be used as a basis for discussing individual strengths and weaknesses leading to suggestions for improved performance. Once the candidate is selected during the OPA, training and development programmes can be tailored to the candidate's individual developmental requirements regarding key activities identified during the selection process. Thus, a training and development programme benefits from the input of the rating scales.

Within the military context, leadership elements may frequently be promoted or moved within the organisation, leaving uncertainty regarding the processes followed. The behaviour-anchored scale utilised during this process adds stability to the system by specifying the valued behaviours for both new leadership and its employees. In essence, it is a system that goes beyond the changing of leadership.

\section{Conclusion}

This article focused on describing the procedural review of the Special Forces officer's potential assessment process. The four-stage redesigned model utilised guided the client (Special Forces) as well as the subject matter experts and psychologists to a detailed analysis of the assessment centre process followed. Critical analysis of both the process and assessment instruments identified a need for a streamlined assessment process, which reduces rater cognitive overload. In addition, redesigning the rating instruments focused on well-defined, practical, work-related behaviours, which could be measured on various occasions to identify suitable candidates as well as to identify potential areas for development during the Special Forces basic training cycle. Working collaboratively with the client and capturing their perspectives to the assessment process resulted in a well-rounded process with user-friendly instruments. In addition, the acceptance and trust relationship formed during this process further translated into client training and development measures, ensuring the stability and standardisation for future OPA processes.

\section{Future research}

With regard to the South African Special Forces Officers potential assessment, a large scope for future research exists. Some areas for possible future research are:

- Assessing the candidates with regard to performance during the preexhaustion, exhaustion and recovery phases. This is seen as an important aspect that can be capitalised on as the individual's performance under stress can be clearly observed once mental and physical exhaustion sets in. The individual's performance during the pre-exhaustion and exhaustion phases could also be compared.

- Currently, the Special Forces School is experiencing challenges with regard to some candidates being highly motivated and eager to undergo the selection process and to qualify as operators; however, as time progresses, 
it seems some candidates are losing their motivation and drive. Attitude assessments could thus be utilised during the pre-selection phase and should be re-tested during the second half of Special Forces individual phase. This will ensure that a candidate's motivation can be monitored continuously during the selection process. In addition, it may provide valuable insights with regard to the loss of motivation and drive during the later stages of the selection process.

\section{Endnotes}

${ }^{1}$ JD McNally, TJ Ligthelm \& S Martin (eds). Military Health Support Doctrine: Landward conventional operations. Simon's Town: SA Naval Publication Unit, 2012.

2 JW O'Neill. "SA Special Forces basic operator psychological profile manual”. Unpublished manual. Pretoria: Military Psychological Institute, 2009, 4.

${ }^{3}$ Employment Equity Act, Act 55 of 1998; D Meiring \& A Buckett. "Best practice guidelines for the use of the assessment centre method in South Africa $5^{\text {th }}$ edition". SA Journal of Industrial Psychology 42/1. 2016. 1-15.

${ }^{4}$ Ibid.; C Bieri \& P Schuler. "Cross-curricular competencies of student teachers: A selection model based on assessment centre admission tests and study success after the first year of teacher training". Assessment \& Evaluation in Higher Education 36/4. 2011. 399-415; AM Herd, M Alagaraja \& DM Cumberland. "Assessing global leadership competencies: The critical role of assessment centre methodology". Human Resource Development International 19/ 1. 2016. 27-43.

${ }^{5}$ Meiring \& Buckett op. cit.; S Schlebusch \& G Roodt. Assessment centres: Unlocking potential for growth. Randburg: Knowres, 2008; BJ Hoffman, KG Melchers, CA Blair, M Kleinmann \& RT Ladd. "Exercises and dimensions are the currency of assessment centers". Personnel Psychology 64. 2011. 351-395.

${ }^{6}$ Employment Equity Act, Act 55 of 1998; PF Erasmus. Situation specific job profiling and assessment in the workplace of the 21 st century. Johannesburg: Potential Index Associates, 2001; Meiring \& Buckett op. cit.

${ }^{7}$ Herd et al. op. cit.; TN Garavan. "Using assessment centre performance to predict subjective person-organisation (P-O) fit: A longitudinal study of graduates". Journal of Managerial Psychology 22/2. 2007. 150-167.

${ }^{8}$ Ibid.; Meiring \& Buckett op. cit.

${ }^{9}$ Ibid.; Garavan op. cit.

${ }^{10}$ A Mitchell Gibbons \& DE Rupp. "Dimension consistency as an individual difference: A new (old) perspective on the assessment center construct validity debate". Journal of Management 35/5. 2009. 1154-1180.

${ }^{11}$ Meiring \& Buckett op. cit.; Schlebusch \& Roodt op. cit.; Mitchell Gibbons \& Rupp op. cit.

${ }^{12}$ Meiring \& Buckett op. cit. 
${ }^{13}$ Ibid. 4.

${ }^{14}$ Schlebusch \& Roodt op. cit.

${ }^{15}$ Ibid.

${ }^{16}$ Meiring \& Buckett op. cit.; Schlebusch \& Roodt op. cit.; R Edenborough. Assessment methods in recruitment, selection and performance: A manager's guide to psychometric testing, interviews and assessment centres. London: Kogan Page, 2005.

${ }^{17}$ Schlebusch \& Roodt op. cit.

${ }^{18}$ Meiring \& Buckett op. cit; ; UJ Wiersema, PT van den Berg \& GP Latham.

"Dutch reactions to behavioral observation, behavioral expectation and trait scales". Group \& Organization Management 20/3. 1995. 297-309.

${ }^{19}$ Ibid.; GP Latham \& GH Seijts. "The effect of appraisal instrument on managerial perceptions of fairness and satisfaction with appraisals from their peers". Canadian Journal of Behavioural Science 29/4. 1997. 275-282.

${ }^{20}$ Ibid.

${ }^{21}$ Ibid.

${ }^{22}$ Wiersema et al. op. cit.; Latham \& Seijts op. cit.

${ }^{23} \mathrm{~N}$ Sawardekar. Assessment centres: Identifying potential and developing competency. New Delhi: Response Books, 2002.

${ }^{24}$ Ibid.

${ }^{25}$ Ibid.

${ }^{26}$ DA Devcich, J Weller, SJ Mitchell, S McLaughlin, L Barker, JW Rudolph, DB Raemer, M Zammert, SJ Singer, J Torrie, CMA Frampton \& AF Merry. "A behaviourally anchored rating scale for evaluating the use of the WHO Surgical Safety Checklist: Development and initial evaluation of the WHOBARS". BMJ Quality and Safety 25/10. 2015. 778-786. <https:// qualitysafety.bmj.com/content/25/10/778.citation-tools $>$ Accessed on 1 February 2018.

${ }^{27}$ A Tziner, C Joanis \& KR Murphy. "A comparison of three methods of performance appraisal with regard to goal properties, goal perception and ratee satisfaction". Group and Organisation Management 25/2. 2000. 175-190; GA Bolt. "Psychometric characteristics of the Behavioural Observation Scale”. Master's thesis. Western Michigan University, 1984. $<$ http://scholarworks.wmich.edu/masters.thesis $\geq$ Accessed on 1 February 2018.

${ }^{28}$ Ibid.

${ }^{29}$ Devcich et al. op. cit.

${ }^{30}$ Bolt op. cit.; Devcich et al. op. cit.

${ }^{31}$ Herd et al. op. cit.; Wiersema et al. op. cit.

${ }^{32}$ Devcich et al.op. cit.

${ }^{33}$ M Martin-Rough, RJ Tannenbaum, CM Tocci \& C Reese. "Behaviorally anchored rating scales: An application for evaluating teaching practice". Teaching and Teacher Education 59. 2016. 414-419.

${ }^{34}$ NMA Hauenstein, RD Brown \& AL Sinclair. "BARS and those mysterious, missing middle anchors". Journal of Business Psychology 25. 2010. 663-672. 
${ }^{35}$ Martin-Rough et al. op. cit.; Hauenstein et al. op. cit.

${ }^{36}$ Schlebusch \& Roodt op. cit.

${ }^{37}$ Mitchell Gibbons \& Rupp op. cit.

${ }^{38}$ Meiring \& Buckett op. cit.; DJR Jackson, SG Atkins, RB Fletcher \& JA Stiilman. "Frame of reference training for assessment centers: Effects on interrater reliability when rating behaviours and ability traits". Public Personnel Management 34/1. 2005. 17-30.

${ }^{39}$ I Ballantyne \& P Nigel. Assessment and development centres ( $2^{\text {nd }}$ ed). Burlington, VT: Gower, 2004.

${ }^{40}$ Ibid.; Schlebusch \& Roodt op. cit.; Meiring \& Buckett op. cit.

${ }^{41}$ Schlebusch \& Roodt op. cit.

${ }^{42}$ Meiring \& Buckett op. cit.

${ }^{43}$ Jackson et al. op. cit.; DJ Schleicher, DV Day, BT Mayes \& RE Riggio. "A new frame for frame-of-reference training: Enhancing the construct validity of assessment centers". Journal of Applied Psychology 87. 2002. 735-746.

${ }^{44}$ Schlebusch \& Roodt op. cit.

${ }^{45}$ Meiring \& Buckett op. cit.; Garavan op. cit.

${ }^{46}$ Meiring \& Buckett op. cit.

${ }^{47}$ Ibid.

${ }^{48}$ KG Melchers, M Kleinmann \& MA Prinz. "Do assessors have too much on their plates? The effects of simultaneously rating multiple assessment center candidates on rating quality". International Journal of Selection and Assessment 18/3. 2010. 329-341.

${ }^{49}$ Mitchell Gibbons \& Rupp op. cit.

${ }^{50}$ Meiring \& Buckett op. cit.

${ }^{51}$ Ibid.

${ }^{52} \mathrm{Ibid}$.

${ }^{53}$ Mitchell Gibbons \& Rupp op. cit.

${ }^{54}$ Meiring \& Buckett op. cit.

${ }^{55}$ Ibid.

${ }^{56}$ O'Neill op. cit.

${ }^{57}$ South African National Defence Force. Special Forces Brigade Force Preparation. 3/2004 edition No. 01. SANDF unpublished policy document, 2004.
${ }^{58} \mathrm{Ibid}$.
${ }^{59}$ Ibid.
${ }^{60}$ Ibid.
${ }^{61}$ Ibid.
${ }^{62}$ Ibid.
${ }^{63}$ Ibid.
${ }^{64}$ Schlebusch \& Roodt op. cit.
${ }^{65}$ Ibid.
${ }^{66}$ Ibid.; Meiring \& Buckett op. cit. 